\title{
Effect of Almond Supplementation on Glycemia and Cardiovascular Risk Factors in Asian Indians in North India with Type 2 Diabetes Mellitus: A 24-Week Study
}

\author{
Seema Gulati, $\mathrm{PhD},^{1-3}$ Anoop Misra, $\mathrm{MD}^{1-5}$ and Ravindra M. Pandey, $\mathrm{PhD}^{6}$
}

\begin{abstract}
Background: Type 2 diabetes (T2D) statistics have reached menacing proportions in India. Appropriate dietary intervention, as part of healthy lifestyle, is imperative to curb further spread of this disease.

Objectives: This pre-post intervention study was conducted in New Delhi, India, to investigate the effects of daily consumption of almonds for 24 weeks in T2D subjects, specifically on measures of glycemia and cardiovascular disease (CVD) risk factors.

Methods and Study Design: In this study, the 24-week intervention period was preceded by a control diet and exercise run-in period of 3 weeks. Raw almonds (20\% of energy intake) were provided to the patients for consumption along with diet and physical activity counseling. Patients were assessed for anthropometry, blood pressure, measures of glycemia (fasting blood glucose, glycosylated hemoglobin), lipids [total cholesterol (TC), triglycerides, high-density lipoprotein-cholesterol, low-density lipoprotein-cholesterol, lipoprotein(a)], surrogate marker of atherosclerosis (Pulse wave velocity), and marker of inflammation (high sensitivity C-reactive protein [hs-CRP]) at baseline and after the intervention period.

Results: Statistically significant improvement in mean values for various parameters post intervention was as follows: waist circumference $(P<0.03)$, waist-to-height ratio $(P<0.005)$, TC $(P<0.002)$, serum triglycerides $(P<0.004)$, low-density lipoprotein cholesterol $(P<0.01)$, glycosylated hemoglobin $(P<0.04)$, and hs-CRP $(P<0.01)$. A trend toward improvement in pulse wave velocity $(P<0.06)$ was also observed.

Conclusion: The study findings illustrate that incorporation of almonds in a well-balanced healthy diet leads to multiple beneficial effects on glycemic and CVDs risk factors in Asian Indian patients with T2D.
\end{abstract}

Keywords: type 2 diabetes, Asian Indians, almonds, cardiovascular disease, glycemia

\section{Introduction}

$\mathrm{D}$ ESPITE EARLY KNOWLEDGE of the symptoms of diabetes, as evident from their reference in medical texts originating in India as far back as $2000-2500 \mathrm{BC}^{1}{ }^{1}$ the spread of this menacing disease has reached epic proportions today. Ironically, India is now considered the diabetes capital of the world. ${ }^{2}$
The International Diabetes Federation (IDF) 2015 estimate of 69.2 million people with type 2 diabetes (T2D) in India is predicted to double before the year $2040 .^{3}$ Although IDF has reported the current prevalence of $\mathrm{T} 2 \mathrm{D}$ in Indian adults at about $8.5 \%,{ }^{3}$ recent research in India provides far more disturbing statistics. A study carried out across 11 Indian states to ascertain the prevalence of $\mathrm{T} 2 \mathrm{D}$ in middle-class urban

\footnotetext{
${ }^{1}$ Diabetes Foundation (India), SDA, New Delhi, India.

${ }^{2}$ National Diabetes, Obesity and Cholesterol Foundation (N-DOC), New Delhi, India.

${ }^{3}$ Center of Nutrition \& Metabolic Research (C-NET), New Delhi, India.

${ }^{4}$ Fortis C-DOC Center of Excellence for Diabetes, Metabolic Diseases and Endocrinology, New Delhi, India.

${ }^{5}$ Fortis Flt. Lt. Rajan Dhall Hospital, Vasant Kunj, New Delhi, India.

${ }^{6}$ All India Institute of Medical Sciences (AIIMS), New Delhi, India.
}

(C) Seema Gulati, et al., 2017; Published by Mary Ann Liebert, Inc. This Open Access article is distributed under the terms of the Creative Commons Attribution Noncommercial License (http://creativecommons.org/licenses/by-nc/4.0/) which permits any noncommercial use, distribution, and reproduction in any medium, provided the original author(s) and the source are credited. 
Indians found an age-adjusted known or diagnosed prevalence of $16 \%,{ }^{4}$ with more than $25 \%$ of diabetics undiagnosed.

A 10-year follow-up to the Chennai Urban Rural Epidemiology Study (CURES) found $26 \%$ of subjects with normal glucose tolerance converting to prediabetes, and another $20 \%$ converting to diabetes, with an overall dysglycemia conversion rate of $45 \%$ and no sex-wise differences observed. ${ }^{5}$ The incidence rate of diabetes in the same study was 79 per 1000 person-years, one of the highest reported in a large ethnic group and twice the rate for Caucasians (3540 per 1000 person years). ${ }^{5}$ Not only is the disease spreading at an alarming rate, but it also seems to be cutting across all social, demographic, and age groups in India.

Initially recognized as a disease of affluent migrants, ${ }^{6}$ T2D seems to be extending its strong foothold across all Indian population types. A recent cross-sectional analysis of representative samples of subjects from a South-Asia study and another for South Asians living in America showed a higher age-adjusted diabetes prevalence among Indians in India (38\%) than among Indians residing in the United States $(24 \%))^{7}$ Another recent study in Maharashtra, India, to assess the risk factors for T2D among three different social and demographic class groups-affluent medical students, rural subjects, and subjects from urban slumsdemonstrated that the rural subjects, although the least sedentary and significantly more active than the medical students, were most centrally obese and at a higher risk for T2D compared with the two other groups. ${ }^{8}$

Symptoms of the disease are not just widespread but are also occurring at a younger age. A cross-sectional study of Indian adolescents in rural Wardha (central India) found $14 \%$ of subjects with impaired fasting blood glucose (FBG) values. ${ }^{9}$

In addition, the burden of dysglycemia is known to translate into additional disease burdens, such as hypertension, ${ }^{10}$ cardiovascular disease (CVD), ${ }^{11}$ metabolic syndrome, ${ }^{9}$ nonalcoholic fatty liver disease, ${ }^{12}$ diabetic nephropathy, ${ }^{13}$ diabetic retinopathy, liquefaction and syneresis of the vitreous ${ }^{14}$ peripheral neuropathy leading to foot ulceration and even amputation, ${ }_{16}^{15}$ potential increased predisposition to hepatitis $\mathrm{C}$ infection, ${ }^{16}$ and co-morbid depression. ${ }^{17,18}$ The cost of dealing with diabetes and its complications translates into a colossal economic burden for the country and its people. ${ }^{19}$

Several factors are known to play a role in dictating the onset of prediabetes and the progression to T2D among Indians. However, the primary factor postulated for higher and earlier incidence in Indians versus other ethnicities has come to be known as the "South Asian" or the "Asian Indian" phenotype, which is characterized by higher waist circumference, higher levels of total and visceral fat, hyperinsulinemia, insulin resistance, and, thus, a great predisposition to diabetes compared with some other ethnicities with comparable body mass index (BMI). ${ }^{5}$ With a genetic predisposition to insulin resistance and T2D, it is imperative that Indians adopt lifestyle modifications to help delay prediabetes onset and to manage the disease better. Nutrition is an important aspect of a healthy lifestyle. A recent review of the nutrient intake of Asian Indian and South Asian diets reveals a low intake of monounsaturated fatty acid (MUFA), polyunsaturated fatty acid (PUFA), and fiber and high intake of saturated fats, trans-fatty acids, and carbohydrates. ${ }^{20}$

The required change in Indian dietary patterns should be inclusion of nutritious foods that are already part of Indian culture and can easily be accommodated into the everyday diet. Almonds fit the requirements of a food item that is not only culturally trusted and accepted for its nutritional value, ${ }^{21}$ but has also been clinically proven to impart the health benefits necessary to help manage dysglycemia and its disease manifestations, which are known to impact cardiometabolic health. ${ }^{22-25}$ Results from these and other successful clinical studies of almond intervention provide sufficient data and confidence to test the effects of almond consumption on health outcomes in Indian subjects, despite their unique "Asian Indian" phenotype. This study was therefore conducted to investigate the effects of daily consumption of almonds for 24 weeks in T2D subjects, specifically on measure of glycemia and CVD risk factors.

\section{Materials and Methods}

\section{Study population}

Patients with T2D were recruited through physician referral at the outpatient department of the Fortis C-DOC Center of Excellence for Diabetes, Metabolic Diseases and Endocrinology, Delhi. In accordance with the inclusion criteria, the study staff recruited patients in the age range of 25-70 years, on stable doses of metformin for a period of 3 months, with glycosylated hemoglobin (HbA1c) levels $<9 \%$, and low-density lipoprotein cholesterol (LDL-c) levels $\geq 100 \mathrm{mg} / \mathrm{dL}$. The study excluded subjects on insulin therapy, pioglitazone, insulin secretagogues, beta blockers or steroids, or those suffering from diabetes for more than 10 years. Subjects with high uric acid levels $(\geq 8 \mathrm{mg} / \mathrm{dL})$ and accelerated hypertension (stage 2 hypertension according to the Joint National Committee guidelines), ${ }^{26}$ uncontrolled hypothyroidism, acute infection, any debilitating disease, renal failure, or appreciable weight loss $(>10 \%)$ in the previous 6 months were also excluded from the study. Patients were screened for any known food allergies, lipidaltering medications, or extraneous factors that are known to affect glycemic or lipid parameters.

\section{Ethics committee statement}

An independent review committee, "Ethics Committee for Human Research," approved the study protocol with the statement-The Ethics Committee hereby gives an approval to conduct the study at Fortis Flt. Lt. Rajan Dhall Hospital, Vasant Kunj, New Delhi. Written informed consent form, approved by the ethics committee, was obtained from all the study participants.

The study was registered at clinicaltrials.gov with registration number NCT02027740.

\section{Study design}

A free-living pre-post intervention study design was used to assess the effect of almond supplementation over a period of 24 weeks after a run-in control period of 3 weeks. The study was designed as a pre-post intervention to ensure that all subjects received almond treatment. During the run-in period $(n=63)$, all subjects consumed standard diets formulated according to the dietary guidelines for Asian Indians, appropriate to the diabetes status of the individual. The diet composition of the control diet was as follows: carbohydrates, $60 \%$; protein, $15 \%$; and fat, $25 \%$. Subjects were advised $45 \mathrm{~min}$ of walking at least 5 days in a week and 
Table 1. Changes in Outcome Variables After Run-In Period

\begin{tabular}{lcccc}
\hline Variable & $\begin{array}{c}\text { Screening } \\
\text { Mean } \pm \text { SD }\end{array}$ & $\begin{array}{c}\text { After } 3 \text { weeks } \\
\text { Mean } \pm S D\end{array}$ & Difference $(95 \%$ CI) & P-value \\
\hline Total cholesterol (mg/dL) & $201.4 \pm 31.4$ & $202.3 \pm 31.4$ & $0.9(-6.8,8.6)$ & 0.802 \\
Serum triglycerides (mg/dL) & $182.5 \pm 87.5$ & $195.3 \pm 112.1$ & $12.8(-9.1,34.8)$ & 0.212 \\
Low-density lipoprotein (mg/dL) & $133.9 \pm 19.7$ & $131.1 \pm 21.4$ & $-2.8(-8.3,2.6)$ & 0.330 \\
High-density lipoprotein (mg/dL) & $41.7 \pm 9.3$ & $42.1 \pm 8.9$ & $0.4(-1.1,1.9)$ & 0.635 \\
Very low-density lipoprotein (mg/dL) & $38.9 \pm 22.2$ & $36.7 \pm 18.2$ & $2.3(-2.3,6.9)$ & 0.342 \\
Fasting blood glucose (mg/dL) & $133.9 \pm 31.3$ & $131.9 \pm 29.2$ & $-1.9(-7.8,3.8)$ & 0.511 \\
Glycosylated hemoglobin (\%) & $7.9 \pm 1.7$ & $7.7 \pm 1.2$ & $-0.2(-0.5,0.1)$ & 0.128 \\
\hline
\end{tabular}

$\mathrm{SD}$, standard deviation.

were asked to maintain the same level of physical activity throughout the study period. The subjects enrolled for the study were patients with T2D, already attending the outpatient department frequently for treatment. These patients were previously given standardized diet and exercise counseling repeatedly and were following such advice before recruitment in the study.

\section{Diet and compliance}

After the run-in period, during the treatment phase, subjects received the almond diet and were advised on how to substitute $20 \%$ of total energy intake with whole raw almonds (unblanched kernels, with brown skin intact). In the almond diet, almonds were substituted for some visible fat (cooking oil and butter) and a portion of carbohydrates. The dietary composition of the almond diet was as follows: carbohydrates, 55\%; protein, $17 \%$; and fat, $28 \%$. Instructions were provided verbally and in writing according to the subject's local language.

Compliance to the study protocol was ensured through compliance questionnaires, biweekly telephone calls with subjects, and cross-checks with spouses or family members residing with the subjects. In addition, subjects were asked to return empty almond packets on their hospital visits. Spouses and family members were also given a supply of almonds for daily consumption to help ensure subject compliance. Subject compliance to the protocol was found to be nearly $85 \%$.

\section{Assessments}

Each subject's right arm was used for blood pressure measurement. According to standard protocol, the subject was required to be in a relaxed sitting position. ${ }^{26}$ Assessments for anthropometric, glycemia [FBG and glycosylated hemoglobin $(\mathrm{HbA} 1 \mathrm{c})$ ], and lipid parameters [total cholesterol (TC), serum triglycerides (TG), LDL-C, high-density lipoprotein cholesterol (HDL-C), and very low-density lipoprotein cholesterol (VLDL-C)] were carried out as described previously. ${ }^{27}$ BMI and waist-to-height ratio (WHtR) were calculated. HbA1c, lipoprotein(a) [Lp(a)], and high sensitivity C-reactive protein (hs-CRP) levels were measured as described previously. ${ }^{28-30}$ Arterial stiffness indices were assessed noninvasively by measuring carotid-femoral pulse wave velocity with a SphygmoCor cuff (Atcor Medica, Australia). Assessments listed above were conducted on the first day of enrollment, the last day of the run-in period, and the last day of the almond intervention period.

\section{Statistical methodology}

Data were recorded on predesigned case report forms and managed on Excel spreadsheets. Quantitative variables were summarized as mean \pm standard deviation or median (range) as per their distribution (normal/non-normal). A paired $t$-test was used to compare pre- to post intervention differences in mean values. The Wilcoxon signed-rank test was used to compare pre intervention (after the run-in period) to postintervention differences in median values. STATA 11.0 statistical software was used for data analyses.

All the parameters were compared at the beginning and at the end of run-in period. There was no significant difference between before and after the run-in period in all the considered biochemical and anthropometric parameters (Table 1).

\section{Results}

\section{Study population}

Study staff screened 190 subjects and enrolled 63 of these subjects on the basis of inclusion/exclusion criteria mentioned above (Fig. 1). Five of the enrolled subjects dropped out of the study during the run-in period: three due to relocation and two due to personal reasons not related to the study. A total of 58 subjects completed the run-in period. Another three subjects withdrew before the treatment phase for personal reasons. A total of 55 subjects began the almond intervention, and a total of 50 subjects completed the study (Fig. 1), with two out of five dropouts lost to followup and the remaining three lost to poor compliance. Of the 50 completers, there were 27 males and 23 females, with an overall mean age of $45.8 \pm 9.3$ year and a mean body weight of $73.6 \pm 12.1 \mathrm{~kg}$, waist circumference of $99.4 \pm 9.2 \mathrm{~cm}$, and BMI of $28.7 \pm 4.5 \mathrm{~kg} / \mathrm{m}^{2}$ (Table 2).

\section{Anthropometry and blood pressure}

There was no significant change in body weight and BMI, but significant decreases in mean values of waist circumference $(P=0.03)$ and WHtR $(P=0.05)$ were observed after almond intervention compared with the control diet given in the run-in period (Table 2). Blood pressure measurements did not change significantly post intervention compared with the control diet.

\section{Measures of glycemia}

FBG levels did not show a significant change over the course of the study (Table 2). Statistically significant improvement was seen in levels of HbA1c $(P=0.04)$ after almond intervention compared with the control diet (Table 2). 


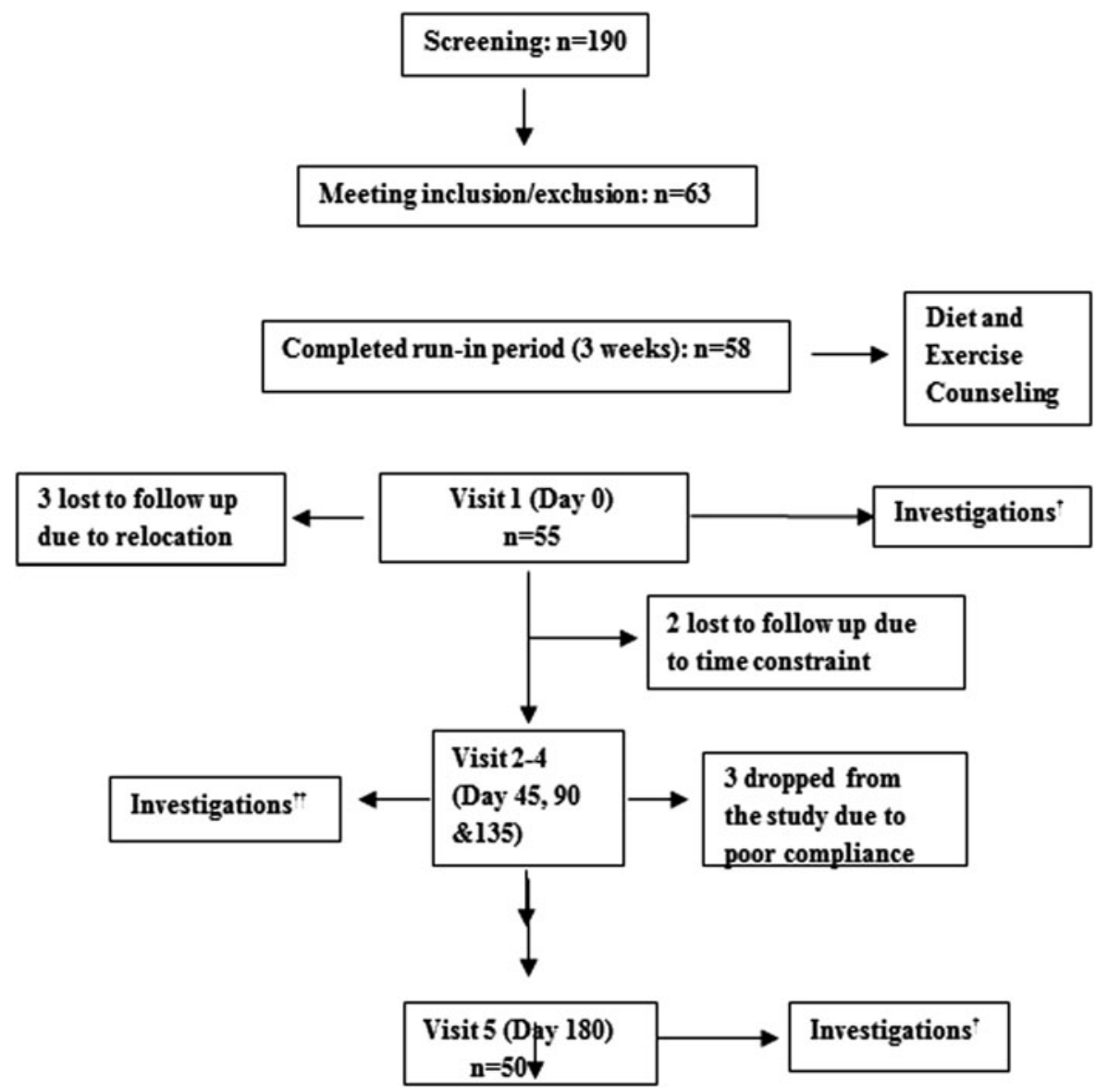

FIG. 1. 'Investigation: anthropometry, blood pressure, fasting blood glucose (FBG), glycosylated hemoglobin (HbAlc), total cholesterol (TC), serum triglycerides (TG), highdensity lipoprotein cholesterol (HDLC), low-density lipoprotein cholesterol (LDL-C), lipoprotein(a) (LP(a)), high sensitivity C-reactive protein (hs-CRP), pulse wave velocity, diet, and physical activity assessments. †'Investigations: anthropometry, blood pressure, FBG, lipids (TC, TG, HDLC, LDL-C).

\section{Lipid parameters}

Statistically significant improvements in levels of TC $(P=0.002)$, TG $(P=0.004)$, LDL-C $(P=0.01)$, VLDL-C $(P=0.007)$, and hs-CRP $(P=0.01)$ were observed postintervention (Table 2). HDL-C did not change and $\mathrm{Lp}(\mathrm{a})$ demonstrated a trend toward reduction, although the decrease failed to attain statistical significance (Table 2). Pulse wave velocity also demonstrated an improvement postintervention, however, the change was not statistically significant $(P>0.06)$.

\section{Discussion}

This study demonstrated that daily almond consumption at $20 \%$ of total energy intake for 24 weeks helped improve anthropometric, glycemic, and lipid parameters significantly in Asian Indian subjects with T2D.

An intake of whole almonds adds protein, total dietary fiber, MUFAs, PUFAs, vitamin E, and potassium ${ }^{31}$ to the diet and has been shown by others to improve the quality of diet without increasing energy intake. ${ }^{23,32}$ There is evidence from other almond supplementation studies collectively that almonds may have a greater impact on multiple cardiometabolic health parameters in the same subjects. ${ }^{25,33}$ These multiple health benefits were observed in the current study as well. Waist circumference and WHtR decreased significantly after almond supplementation (Table 2) and may well explain the benefits on glycemia and lipid parameters observed in the subjects.
In addition to improved anthropometric measures, this study demonstrated a statistically significant decrease in HbAlc levels in subjects after almond supplementation compared with their levels on the control diet. HbA1C has been validated for the diabetic Asian Indian population. ${ }^{34}$ The HbA1c results from this study are comparable, maybe even better, to those obtained in other nut intervention studies (Table 3).

High $\mathrm{HbA} 1 \mathrm{C}$ has been found to be associated with greater waist circumference and higher serum triglycerides. ${ }^{35}$ Subjects in the current study demonstrated a concurrent and significant decrease in HbA1C, waist circumference, and serum triglycerides (Table 2), thereby providing strong evidence in support of this association. It has also been clinically proven and scientifically accepted that any reduction in levels of HbA1C significantly decreases the risk of diabetic complications. ${ }^{36}$ Although the incidence of diabetic complications was not recorded in this study due to its limited duration, the benefits of daily almond intake have been shown by others to reduce risks of complications. ${ }^{33}$

The benefits of almonds on postprandial glucose regulation have been clearly and consistently demonstrated in many studies. ${ }^{22,23,41,42}$ However, results from studies looking at benefits resulting from chronic consumption have been mixed. Although Li et al. ${ }^{25}$ demonstrated a statistically significant reduction in fasting glucose in 58-year-old Taiwanese subjects with T2D on a $60 \mathrm{~g}$ daily dose of almonds for 4 weeks, the current study failed to demonstrate a statistically significant difference on fasting glucose levels. 


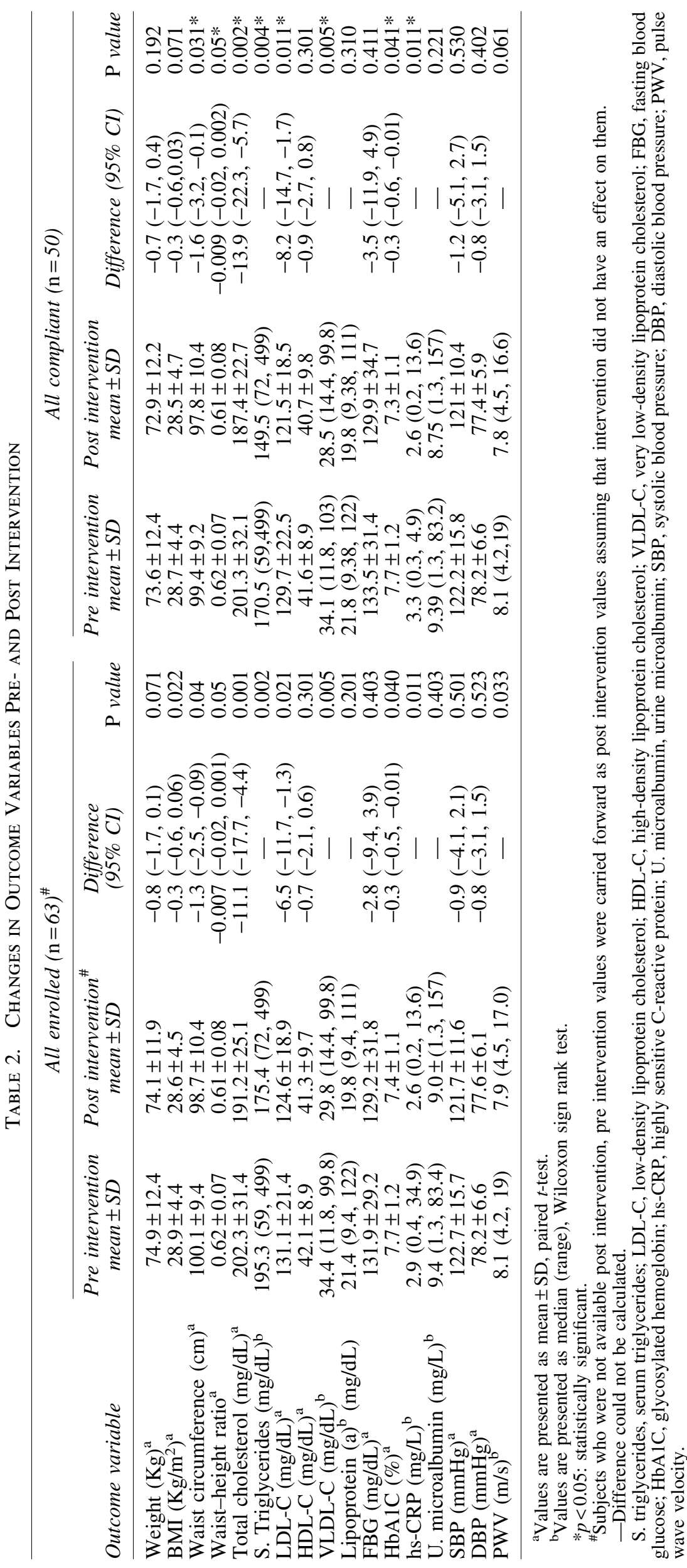


Table 3. Comparison of HbA1C Value After Intervention with Tree Nuts in Selected Studies

\begin{tabular}{|c|c|c|c|c|c|c|c|}
\hline Study & $\begin{array}{l}\text { Subject type; } \\
\text { completers (n) }\end{array}$ & $\begin{array}{c}\text { Subject } \\
\text { age (year) }\end{array}$ & $\begin{array}{l}\text { Nut treatment: } \\
\text { amount }(g)\end{array}$ & $\begin{array}{l}\text { Intervention } \\
\text { duration } \\
\text { (month) }\end{array}$ & $\begin{array}{l}\text { Baseline } \\
\text { HbAlc (\%) }\end{array}$ & $\begin{array}{c}\text { End of intervention } \\
\text { HbAlc }(\%)\end{array}$ & $\mathrm{P}$ value \\
\hline Tapsell et al. ${ }^{37}$ & T2D ${ }^{\mathrm{a}} ; 18$ & $54 \pm 8.7$ & Walnuts: 30 & 6 & $7.3 \pm 1.2$ & $7.1 \pm 1.5$ & 0.023 \\
\hline Jenkins et al. ${ }^{38}$ & $\mathrm{~T} 2 \mathrm{D}^{\mathrm{a}} ; 40$ & 63 & $\begin{array}{l}\text { Mixed nuts: } \\
50-100\end{array}$ & 3 & $7.1 \pm 0.2$ & $6.9 \pm 0.2$ & 0.001 \\
\hline Cohen et al. ${ }^{39}$ & $\mathrm{~T} 2 \mathrm{D}^{\mathrm{a}} ; 6^{\mathrm{b}}$ & $66.0 \pm 3.3$ & Almonds: 28 & 3 & $7.1 \pm 0.2$ & $6.8 \pm 0.3$ & 0.045 \\
\hline Gulati et al. ${ }^{40}$ & $\operatorname{MetS}^{c} ; 30$ & $41.6 \pm 8.4$ & Pistachios & 6 & $5.9 \pm 0.4$ & $5.7 \pm 0.3$ & 0.301 \\
\hline
\end{tabular}

${ }^{\mathrm{a}} \mathrm{T} 2 \mathrm{D}$ refers to type 2 diabetes subject type.

${ }^{\mathrm{b}}$ Pilot study.

${ }^{\mathrm{c}}$ MetS refers to subjects with metabolic syndrome as per modified International Diabetes Federation definition.

With no difference observed in fasting glucose and in the absence of fasting insulin measures, it is difficult to postulate the potential mechanism of action involved in the other observed benefits.

Similar results for fasting glucose levels have been observed in several mixed-nuts studies with almond intake. Despite reporting a significant improvement in $\mathrm{HbA1c}$, insulin resistance, insulin sensitivity, or insulin levels, these studies have failed to show a change in FBG. ${ }^{38,43,44}$ These results suggest that the preferred mechanism of action of almonds behind long-term glycemic control might be through a pivotal role in insulin management rather than in reduction of glucose absorption or increased clearance.

The relationship between fasting blood lipid levels, particularly levels of LDL-C and TC, and the risk of CHD is well established in the scientific literature. ${ }^{45-47}$ Specifically, for every $1 \%$ reduction in $\mathrm{LDL}-\mathrm{C}$, there is a corresponding $1 \%-2 \%$ decrease in the risk of CHD. ${ }^{45,48}$ Results from the current study demonstrated a statistically significant decrease in levels of TC, LDL-C, and VLDL-C after almond supplementation in study subjects compared with intake of the control diet. Comparable results have been observed in multiple studies conducted using similar almond intake. ${ }^{49-54}$ As observed in other almond consumption studies, HDL-C did not change significantly after almond consumption when compared with the control diet. ${ }^{52,55-57}$ This might also be indicative of the preferred mechanism of action for almonds, working primarily on the cluster of lower density lipoproteins.

In addition to improved lipid levels, the subjects demonstrated significant improvement in hs-CRP levels. Higher hs-CRP levels in Asian Indian men have been correlated with high fasting insulin levels. ${ }^{58}$ Reduced hs-CRP levels in this study again point to a potential increase in insulin sensitivity. Absence of insulin measures in this study does not confirm this finding, but a substantial decrease in hsCRP does provide strong evidence in that direction.

The current study had a few obvious limitations, particularly the absence of insulin measures, followed by a shorter duration of the control treatment than the test treatment. However, the latter had minimal impact, as the results obtained in this study are quite comparable to studies with equal control and treatment intervention durations. However, effect of slight difference in macronutrient composition in control and intervention diets cannot be completely excluded. It is understandable that slight difference in the macronutrient composition would occur in any such investigational diet compared to control diets. Furthermore, the pre-post design of the study using run-in as control period reduces data variability, thereby increasing the credibility of the results obtained. The role of almonds in insulin management clearly remained elusive and needs further exploration.

In terms of its strength, this is the first study ever demonstrating health benefits of almond consumption in freeliving Asian Indians with T2D, despite their unique Asian Indian phenotype and their predisposition toward the disease. This study provides scientific proof of the value of almond consumption to a population that already believes in the goodness of almonds.

\section{Acknowledgments}

The authors are thankful to all the participants of the study for their cooperation. This study was fully supported by a grant from Almond Board of California, USA.

\section{Author Contributions}

S.G. researched data, conducted the study, wrote the article, A.M. conceived the study idea, supervised the study, wrote the article, reviewed/edited the article, and R.M.P. performed the statistical analysis and reviewed the article.

\section{Author Disclosure Statement}

No competing financial interests exist.

\section{References}

1. Upadhyay OP, Upadhyay D. A few facts of historical interest relating to diabetes mellitus. Indian J Hist Sci 1987; 22:235-239.

2. Gupta A, Agarwal NK, Byadgi PS. Clinical assessment of dietary interventions and lifestyle modifications in Madhumeha (type-2 Diabetes Mellitus). Ауи 2014;35:391-397.

3. International Diabetes Federation. The IDF Diabetes Atlas, 7th Edition 2015. Accessed at www.oedg.org/pdf/1606_ IDF_Atlas_2015_UK.pdf May 5, 2016.

4. Gupta A, Gupta R, Sharma KK, et al. Prevalence of diabetes and cardiovascular risk factors in middle-class urban participants in India. BMJ Open Diabetes Res Care 2014;2: e000048.

5. Anjana RM, Sudha V, Nair DH, et al. Diabetes in Asian Indians-how much is preventable? Ten-year follow-up of the Chennai Urban Rural Epidemiology Study (CURES142). Diabetes Res Clin Pract 2015;109:253-261. 
6. Misra A, Ganda OP. Migration and its impact on adiposity and type 2 diabetes. Nutrition 2007;23:696-708.

7. Gujral UP, Narayan KM, Pradeepa RG, et al. Comparing Type 2 diabetes, prediabetes, and their associated risk factors in Asian Indians in India and in the U.S.: The CARRS and MASALA Studies. Diabetes Care 2015;38:1312-1318.

8. Banerjee A, Rathod H, Konda M, et al. Comparison of some risk factors for diabetes across different social groups: A cross-sectional study. Ann Med Health Sci Res 2014;4: 915-921.

9. Bhalavi V, Deshmukh PR, Goswami K, et al. Prevalence and correlates of metabolic syndrome in the adolescents of rural wardha. Indian J Community Med 2015;40:43-48.

10. Joshi SR, Vadivale M, Dalal JJ, et al. The Screening India's Twin Epidemic: Study design and methodology (SITE-1). Indian J Endocrinol Metab 2011;15 Suppl 4:S389-S394.

11. Chen AH, Tseng $\mathrm{CH}$. The role of triglyceride in cardiovascular disease in asian patients with type 2 diabetes-a systematic review. Rev Diabet Stud 2013 Summer-Fall; 10:101-109.

12. Duseja A, Singh SP, Saraswat VA, et al. Non-alcoholic fatty liver disease and metabolic syndrome-position paper of the Indian National Association for the Study of the Liver, Endocrine Society of India, Indian College of Cardiology and Indian Society of Gastroenterology. J Clin Exp Hepatol 2015;5:51-68.

13. Prasannakumar M, Rajput R, Seshadri K, et al. An observational, cross-sectional study to assess the prevalence of chronic kidney disease in type 2 diabetes patients in India (START -India). Indian J Endocrinol Metab 2015; 19:520-523.

14. Raman R, Ganesan S, Pal SS, et al. Prevalence and risk factors for diabetic retinopathy in rural India. Sankara Nethralaya Diabetic Retinopathy Epidemiology and Molecular Genetic Study III (SN-DREAMS III), report no 2. BMJ Open Diabetes Res Care 2014;2:e000005.

15. Kannan MA, Sarva S, Kandadai RM, et al. Prevalence of neuropathy in patients with impaired glucose tolerance using various electrophysiological tests. Neurol India 2014;62: 656-661.

16. Laloo D, Walke P, Bhimo T, et al. Seroprevalence of hepatitis $\mathrm{C}$ infection in type 2 diabetes mellitus. Indian $\mathrm{J} \mathrm{En-}$ docrinol Metab 2015;19:296-299.

17. Singh H, Raju MS, Dubey V, et al. A study of sociodemographic clinical and glycemic control factors associated with co-morbid depression in type 2 diabetes mellitus. Ind Psychiatry J 2014;23:134-142.

18. Thour A, Das S, Sehrawat T, et al. Depression among patients with diabetes mellitus in North India evaluated using patient health questionnaire-9. Indian J Endocrinol Metab 2015;19:252-255.

19. Yesudian CA, Grepstad M, Visintin E, et al. The economic burden of diabetes in India: A review of the literature. Global Health 2014;10:80.

20. Misra A, Khurana L. Obesity and the metabolic syndrome in developing countries. J Clin Endocrinol Metab 2008;93: S9-S30.

21. Puri A, Sahai R, Singh KL, et al. Immunostimulant activity of dry fruits and plant materials used in indian traditional medical system for mothers after child birth and invalids. J Ethnopharmacol 2000;71:89-92.

22. Jenkins DJ, Kendall CW, Josse AR, et al. Almonds decrease postprandial glycemia, insulinemia, and oxidative damage in healthy individuals. J Nutr 2006;136:29872992.
23. Tan SY, Mattes RD. Appetitive, dietary and health effects of almonds consumed with meals or as snacks: A randomized, controlled trial. Eur J Clin Nutr 2013;67:12051214.

24. Wien M, Bleich D, Raghuwanshi M, et al. Almond consumption and cardiovascular risk factors in adults with prediabetes. J Am Coll Nutr 2010;29:189-197.

25. Li SC, Liu YH, Liu JF, et al. Almond consumption improved glycemic control and lipid profiles in patients with type 2 diabetes mellitus. Metabolism 2011;60:474-479.

26. Chobanian AV, Bakris GL, Black HR, et al. The seventh report of the Joint National Committee on Prevention, detection, evaluation, and treatment of high blood pressure: The JNC 7 report. JAMA 2003;289:2560-2572.

27. Vikram NK, Misra A, Dwivedi M, et al. Correlations of C-reactive protein levels with anthropometric profile, percentage of body fat and lipids in healthy adolescents and young adults in urban North India. Atherosclerosis 2003; 168:305-313.

28. Misra A, Arora N, Mondal S, et al. Relation between plasma leptin and anthropometric and metabolic covariates in lean and obese diabetic and hyperlipidaemic Asian Northern Indian subjects. Diabetes Nutr Metab 2001;14: $18-26$.

29. Vikram NK, Misra A, Pandey RM, et al. Adiponectin, insulin resistance, and C-reactive protein in postpubertal Asian Indian adolescents. Metabolism 2004;53:1336-1341.

30. Vikram NK, Misra A, Pandey RM, et al. Association between subclinical inflammation \& fasting insulin in urban young adult north Indian males. Indian J Med Res 2006; 124:677-682.

31. U.S. Department of Agriculture, Agricultural Research Service. USDA National Nutrient Database for Standard Reference, Release 28; 2015. www.ars.usda.gov/nea/bhnrc/ ndl Accessed on September 1, 2016.

32. Sweazea KL, Johnston CS, Ricklefs KD, et al. Almond supplementation in the absence of dietary advice significantly reduces $\mathrm{C}$-reactive protein in subjects with type 2 diabetes. J Funct Foods 2014;10:252-259.

33. Wien MA, Sabate JM, Ikle DN, et al. Almonds vs complex carbohydrates in a weight reduction program. Int $J$ Obes Relat Metab Disord 2003;27:1365-1372.

34. Kumar PR, Bhansali A, Ravikiran M, et al. Utility of glycated hemoglobin in diagnosing type 2 diabetes mellitus: A community-based study. J Clin Endocrinol Metab 2010; 95:2832-2835.

35. Succurro E, Marini MA, Arturi F, et al. Usefulness of hemoglobin A1c as a criterion to define the metabolic syndrome in a cohort of italian nondiabetic white subjects. Am J Cardiol 2011;107:1650-1655.

36. Stratton IM, Adler AI, Neil HAW, et al. Association of glycaemia with macrovascular and microvascular complications of type 2 diabetes (UKPDS 35): Prospective observational study. BMJ 2000;321:405-412.

37. Tapsell LC, Batterham MJ, Teuss G, et al. Long-term effects of increased dietary polyunsaturated fat from walnuts on metabolic parameters in type II diabetes. Eur J Clin Nutr 2009;63:1008-1015.

38. Jenkins DJ, Kendall CW, Banach MS, et al. Nuts as a replacement for carbohydrates in the diabetic diet. Diabetes Care 2011;34:1706-1711.

39. Cohen AE, Johnston CS. Almond ingestion at mealtime reduces postprandial glycemia and chronic ingestion reduces hemoglobin $\mathrm{A}(1 \mathrm{c})$ in individuals with well-controlled type 2 diabetes mellitus. Metabolism 2011;60:1312-1317. 
40. Gulati S, Misra A, Pandey RM, et al. Effects of pistachio nuts on body composition, metabolic, inflammatory and oxidative stress parameters in Asian Indians with metabolic syndrome: A 24-wk, randomized control trial. Nutrition 2014;30:192-197.

41. Josse AR, Kendall CW, Augustin LS, et al. Almonds and postprandial glycemia - a dose-response study. Metabolism 2007;56:400-404.

42. Mori AM, Considine RV, Mattes RD. Acute and secondmeal effects of almond form in impaired glucose tolerant adults: A randomized crossover trial. Nutr Metab 2011;8:6.

43. Casas-Agustench P, Lopez-Uriarte P, Bullo M, et al. Effects of one serving of mixed nuts on serum lipids, insulin resistance and inflammatory markers in patients with the metabolic syndrome. Nutr Metab Cardiovasc Dis 2011;21: 126-135.

44. Salas-Salvado J, Fernandez-Ballart J, Ros E, et al. Effect of a mediterranean diet supplemented with nuts on metabolic syndrome status: One-year results of the PREDIMED randomized trial. Arch Intern Med 2008;168:2449-2458.

45. LaRosa JC. Low-density lipoprotein cholesterol reduction: The end is more important than the means. Am J Cardiol 2007; 100:240-242.

46. Dembowski E, Davidson MH. A review of lipid management in primary and secondary prevention. J Cardiopulm Rehabil Prev 2009;29:2-12.

47. Preiss D, Sattar N. Lipids, lipid modifying agents and cardiovascular risk: A review of the. Clin Endocrinol (Oxf) 2009;70:815-828.

48. Clark LT. Cholesterol and heart disease: Current concepts in pathogenesis and treatment. J Natl Med Assoc 1986;78: 743-751.

49. Beatrice DA, Shivaji G. Effect of almond supplementation on the anthropometric measurements, biochemical parameters and blood pressure levels of men with metabolic syndrome. Indian J Nutr Dietetics 2015;52:184-191.

50. Abazarfard Z, Salehi M, Keshavarzi S. The effect of almonds on anthropometric measurements and lipid profile in overweight and obese females in a weight reduction program: A randomized controlled clinical trial. J Res Med Sci 2014;19:457-464.
51. Berryman CE, West SG, Fleming JA, et al. Effects of daily almond consumption on cardiometabolic risk and abdominal adiposity in healthy adults with elevated LDLcholesterol: A randomized controlled trial. J Am Heart Assoc 2015;4:e000993.

52. Tamizifar B, Rismankarzadeh M, Vosoughi A, et al. A lowdose almond-based diet decreases LDL-C while preserving HDL-C. Arch Iran Med 2005;8:45-51.

53. Sabate J, Haddad E, Tanzman JS, et al. Serum lipid response to the graduated enrichment of a Step I diet with almonds: A randomized feeding trial. Am J Clin Nutr 2003;77:1379-1384.

54. Jenkins DJ, Kendall CW, Marchie A, et al. Dose response of almonds on coronary heart disease risk factors: Blood lipids, oxidized low-density lipoproteins, lipoprotein(a), homocysteine, and pulmonary nitric oxide: A randomized, controlled, crossover trial. Circulation 2002;106:13271332.

55. Ruisinger JF, Gibson CA, Backes JM, et al. Statins and almonds to lower lipoproteins (the STALL Study). J Clin Lipidol 2015;9:58-64.

56. Jambazian PR, Haddad E, Rajaram S, et al. Almonds in the diet simultaneously improve plasma alpha-tocopherol concentrations and reduce plasma lipids. J Am Diet Assoc 2005; 105:449-454.

57. Spiller GA, Jenkins DA, Bosello O, et al. Nuts and plasma lipids: An almond-based diet lowers LDL-C while preserving HDL-C. J Am Coll Nutr 1998;17:285-290.

58. Ghoshal K, Bhattacharyya M. Adiponectin: Probe of the molecular paradigm associating diabetes and obesity. World J Diabetes 2015;6:151-166.

Address correspondence to: Anoop Misra, MD

Fortis C-DOC Centre of Excellence for Diabetes Metabolic Diseases and Endocrinology

B-16, Chirag Enclave New Delhi-110048 India

E-mail: anoopmisra@gmail.com 